\title{
LA LEGISLACIÓN BÁSICA DE PROTECCIÓN DEL MEDIO AMBIENTE (PRIMER SEMESTRE 2018)
}

\author{
LUCÍA CASADO CASADO \\ Profesora Titular de Derecho Administrativo \\ Universitat Rovira i Virgili
}

Subdirectora

Centre d'Estudis de Dret Ambiental de Tarragona (CEDAT) 
Sumario: 1. Introducción. 2. La intensa acción estatal en el plano internacional. 3. La culminación de la reestructuración organizativa: el nuevo Ministerio de Agricultura y Pesca, Alimentación y Medio Ambiente. 4. Novedades normativas en ámbitos sectoriales. 4.1. En materia de medio marino. 4.2. En materia de patrimonio natural y biodiversidad. 4.3. En materia de fertilizantes. 4.4. En materia de aguas. 4.5. En materia de protección de la atmósfera. 4.6. En materia de responsabilidad medioambiental. 5. Otras normas de interés.

\section{INTRODUCCIÓN}

Durante el período objeto de análisis (del 1 de octubre de 2017 al 30 de marzo de 2018), a nivel estatal, ha habido una escasa actividad normativa en materia ambiental, con novedades de escasa relevancia. Son muy pocas las normas de rango legal aprobadas y también son muy pocas las normas que realmente suponen la introducción de regulaciones innovadoras en materia ambiental, limitándose la mayor parte de ellas a modificar puntualmente regulaciones ya existentes.

En este período, sólo se han aprobado dos normas de rango legal: la Ley $1 / 2018$, de 6 de marzo, por la que se adoptan medidas urgentes para paliar los efectos producidos por la sequía en determinadas cuencas hidrográficas y se modifica el texto refundido de la Ley de Aguas; y el Real Decreto-ley 16/2017, de 17 de noviembre, por el que se establecen disposiciones de seguridad en la investigación y explotación de hidrocarburos en el medio marino.

Así, la casi totalidad de las normas adoptadas tienen rango reglamentario y se adoptan en ámbitos sectoriales muy diversos (patrimonio natural y biodiversidad, fertilizantes, aguas, protección de la atmósfera, responsabilidad medioambiental...). Además, por lo general y salvo alguna excepción destacamos, en este sentido, el Real Decreto 1042/2017, de 22 de diciembre, sobre la limitación de las emisiones a la atmósfera de determinados agentes contaminantes procedentes de las instalaciones de combustión medianas y por el que se actualiza el anexo IV de la Ley $34 / 2007$, de 15 de noviembre, de calidad del aire y protección de la atmósfera; y el Real Decreto 7/2018, de 12 de enero, por el que se establecen los requisitos de documentación, tenencia y marcado en materia de comercio de especies amenazadas de fauna y flora silvestres-, se trata de normas reglamentarias que responden, no tanto a la aprobación de normas completamente nuevas, sino a la modificación de 
normas ya existentes, para mejorar la regulación recogida por las mismas o adaptarlas al Derecho de la Unión Europea, o que afectan a aspectos organizativos.

Así pues, el predominio de normas reglamentarias sigue siendo la tónica predominante a la hora de legislar en materia ambiental. Mayor diversidad existe en cuanto a los títulos competenciales utilizados para aprobar la legislación ambiental en este período. Como tendremos ocasión de comprobar, buena parte de las normas de contenido ambiental aprobadas se adoptan utilizando otros títulos competenciales diferentes al recogido en el artículo 149.1.23 de la CE (legislación básica sobre protección del medio ambiente). Así, el legislador estatal, apela, entre otros, a los títulos competenciales recogidos en los apartados 10 (régimen aduanero y arancelario; y comercio exterior), 13 (bases y coordinación de la planificación general de la actividad económica), 18 (bases del régimen jurídico de las administraciones públicas; procedimiento administrativo común; y legislación básica sobre contratos y concesiones administrativas), 20 (marina mercante), 22 (legislación, ordenación y concesión de recursos y aprovechamientos hidráulicos cuando las aguas discurran por más de una Comunidad Autónoma) y 25 (bases del régimen minero y energético) del artículo 149.1 de la CE, para justificar la aprobación de normas con contenido ambiental.

Como viene siendo habitual, también se ha puesto de manifiesto en este período la conflictividad competencial entre Estado y comunidades autónomas. Buena prueba de ello son, por un lado, los recursos de inconstitucionalidad promovidos por el Presidente del Gobierno contra determinados preceptos de la Ley de Castilla-La Mancha 1/2017, de 9 de marzo, por la que se establecen medidas adicionales de protección de salud pública y del medio ambiente para la exploración, investigación o explotación de hidrocarburos utilizando la técnica de la fractura hidráulica ${ }^{1}$; de la Ley de Cataluña 5/2017, de 28 de marzo, de medidas fiscales, administrativas y del sector público y de creación y regulación de los impuestos sobre grandes establecimientos comerciales, sobre estancias en establecimientos turísticos, sobre elementos radiotóxicos,

\footnotetext{
${ }^{1}$ Admitido a trámite por el Pleno del Tribunal Constitucional, mediante Providencia de 23 de enero de 2018 (BOE núm. 28, de 31 de enero de 2018).
} 
sobre bebidas azucaradas envasadas y sobre emisiones de dióxido de carbono $^{2}$; de la Ley de Cataluña 16/2017, de 1 de agosto, del cambio climático ${ }^{3}$; y de la Ley de Islas Baleares 9/2017, de 3 de agosto, de regulación de las corridas de toros y de protección de los animales ${ }^{4}$. Por otro, el recurso de inconstitucionalidad promovido por más de cincuenta Diputados del Grupo Parlamentario de Unidos Podemos-En Comú Podem-En Marea del Congreso de los Diputados, contra determinados preceptos de la Ley Canaria 4/2017, de 13 de julio, del suelo y de los espacios naturales protegidos de Canarias ${ }^{5}$.

Asimismo, la Sala de lo Contencioso-administrativo del Tribunal Superior de Justicia de Andalucía, con sede en Granada, ha planteado una cuestión de inconstitucionalidad en relación con el artículo 6.1.3 de la Ley 2/1992, de 15 de junio, forestal de Andalucía, por posible vulneración del artículo 149.1.18 de la $\mathrm{CE}^{6}$.

Por otra parte, a través de un Acuerdo de la Comisión Bilateral de Cooperación Administración General del Estado-Comunidad Autónoma de La Rioja, se han resuelto las discrepancias competenciales entre el Estado y esta Comunidad Autónoma en relación con la Ley 6/2017, de 8 de mayo, de protección del medio ambiente de la Comunidad Autónoma de La Rioja ${ }^{7}$; y a través de un Acuerdo de la Comisión Bilateral de Cooperación Administración General del Estado-Comunidad Autónoma de Canarias, las discrepancias en relación con la Ley de Canarias 4/2017, de 13 de julio, del suelo y de los espacios naturales protegidos $^{8}$.

En el ámbito internacional, sí que ha habido una mayor actividad. Destaca, desde esta perspectiva, la ratificación de dos convenios internacionales (el

\footnotetext{
${ }^{2}$ Admitido a trámite por el Pleno del Tribunal Constitucional, mediante Providencia de 23 de enero de 2018 (BOE núm. 28, de 31 de enero de 2018).

${ }^{3}$ Admitido a trámite por el Pleno del Tribunal Constitucional, mediante Providencia de 28 de noviembre de 2017 (BOE núm. 294, de 4 de diciembre de 2017).

${ }^{4}$ Admitido a trámite por el Pleno del Tribunal Constitucional, mediante Providencia de 28 de noviembre de 2017 (BOE núm. 294, de 4 de diciembre de 2017).

${ }^{5}$ Admitido a trámite por el Pleno del Tribunal Constitucional, mediante Providencia de 14 de noviembre de 2017 (BOE núm. 283, de 21 de noviembre de 2017).

${ }^{6}$ Admitido a trámite por el Pleno del Tribunal Constitucional, mediante Providencia de 28 de noviembre de 2017 (BOE núm. 65, de 15 de marzo de 2018).

${ }^{7}$ Vid. BOE núm. 58, de 7 de marzo de 2018.

${ }^{8}$ Vid. BOE núm. 279, de 17 de noviembre de 2017.
} 
Convenio Europeo sobre protección de animales de compañía, hecho en Estrasburgo el 13 de noviembre de 1987; y el Protocolo de Nagoya-Kuala Lumpur sobre responsabilidad y compensación, suplementario al Protocolo de Cartagena, sobre seguridad de la biotecnología, hecho en Nagoya el 15 de octubre de 2010); y la adopción de enmiendas a otros muchos tratados internacionales.

En cuanto a las iniciativas legislativas iniciadas en este período, ha comenzado su tramitación en las Cortes Generales el Proyecto de Ley por la que se modifica la Ley 21/2013, de 9 de diciembre, de evaluación ambiental, la Ley $21 / 2015$, de 20 de julio, por la que se modifica la Ley 43/2003, de 21 de noviembre, de montes y la Ley $1 / 2005$, de 9 de marzo, por la que se regula el régimen del comercio de derechos de emisión de gases de efecto invernadero. Asimismo, se están dando los primeros pasos para declarar un nuevo parque nacional (el Parque Nacional de la Sierra de las Nieves -Málaga-). Mediante Acuerdo del Consejo de Ministros de 9 de febrero de 2018, se ha aprobado, a propuesta del Ministerio de Agricultura y Pesca, Alimentación y Medio Ambiente, la propuesta inicial conjunta de declaración del Parque Nacional de la Sierra de las Nieves. Asimismo, el Ministerio de Agricultura y Pesca, Alimentación y Medio Ambiente continúa trabajando en la elaboración de un borrador de anteproyecto de Ley de cambio climático y transición energética, cuya presentación se prevé para antes del verano. También están en proceso de elaboración nuevas normas reglamentarias, entre las que destacamos la que regula la pesquería de atún rojo en el Atlántico Oriental y Mediterráneo; la que modifica el Reglamento de planificación hidrológica en relación con los planes de sequía; y la instrucción técnica para la elaboración de los planes especiales de actuación ante la sequía.

Por otra parte, el Gobierno ha aprobado el Plan Nacional de Calidad del Aire 2017-2019 (Plan Aire II), con un presupuesto global de 276 millones de euros; y la Conferencia Sectorial de Agricultura y Desarrollo Rural, el Plan Nacional para el Uso Sostenible de Productos Fitosanitarios. Por su parte, el Ministerio de Agricultura y Pesca, Alimentación y Medio Ambiente ha publicado la Estrategia para la Producción Ecológica 2018-2020; y ha sacado a información pública (entre el 12 de febrero y el 12 de marzo de 2018) el borrador de la 
Estrategia Española de Economía Circular. Asimismo, se ha abierto el proceso de información pública para la revisión de los planes especiales de gestión de sequías de todas las cuencas hidrográficas competencia del Estado; y se está trabajando en la elaboración de un Plan de Acción español contra el tráfico ilegal y el furtivismo internacional de especies silvestres.

Por último, también cabe mencionar que, mediante Resolución de 6 de octubre de 2017 de la Secretaría de Estado de Cooperación Internacional y para Iberoamérica y el Caribe, se ha publicado el Convenio de colaboración suscrito entre la Secretaría de Estado de Cooperación Internacional y para Iberoamérica y el Caribe (Ministerio de Asuntos Exteriores y de Cooperación) y la Red Española para el Desarrollo Sostenible (REDS), para la promoción y difusión de la Agenda 2030 de Desarrollo Sostenible, aprobada por la Asamblea General de Naciones Unidas el 25 de septiembre de 2015.

\section{LA INTENSA ACCIÓN ESTATAL EN EL PLANO INTERNACIONAL}

En el período examinado, la acción estatal desarrollada en el plano internacional en materia ambiental ha sido intensa.

En este período, el Estado ha ratificado dos convenios internacionales: el Convenio Europeo sobre protección de animales de compañía, hecho en Estrasburgo el 13 de noviembre de $1987^{9}$, que establece principios comunes sobre la tenencia de animales de compañía y medidas complementarias respecto de los animales vagabundos; y el Protocolo de Nagoya-Kuala Lumpur sobre responsabilidad y compensación, suplementario al Protocolo de Cartagena, sobre seguridad de la biotecnología, hecho en Nagoya el 15 de octubre de $2010^{10}$, cuyo objetivo es contribuir a la conservación y utilización sostenible de la diversidad biológica, teniendo también en cuenta los riesgos para la salud humana y proporcionando normas y procedimientos internacionales en la esfera de la responsabilidad y compensación en relación con los organismos vivos modificados.

\footnotetext{
${ }^{9}$ Instrumento de ratificación de 23 de junio de 2017 (BOE núm. 245, de 11 de octubre de 2017).

${ }^{10}$ Instrumento de ratificación de 9 de agosto de 2012 (BOE núm. 17, de 19 de enero de 2018).
} 
Asimismo, se han adoptado Enmiendas a diferentes instrumentos internacionales ya ratificados. Destacamos las siguientes:

- Instrumento de aceptación de la Enmienda al Convenio sobre evaluación del impacto en el medio ambiente en un contexto transfronterizo, hecha en Cavtat (Croacia) el 4 de junio de $2004^{11}$.

- Enmiendas al Anexo III del Convenio de Róterdam para la aplicación del procedimiento de consentimiento fundamentado previo a ciertos plaguicidas y productos químicos peligrosos objeto de comercio internacional. Decisiones RC-8/2, RC-8/3, RC-8/4 y RC-8/5, adoptadas en Ginebra el 5 de mayo de $2017^{12}$.

- Enmiendas al Anexo II del Convenio Internacional para prevenir la contaminación por los buques, 1973, modificado por el Protocolo de 1978 (Convenio MARPOL), adoptadas mediante Resolución MEPC.270(69) ${ }^{13}$.

- Enmiendas al Código Técnico relativo al control de las emisiones de óxidos de nitrógeno de los motores diésel marinos, adoptadas mediante Resolución MEPC.272(69). (Prueba de los motores de gas y los motores de combustible mixto $)^{14}$.

- Enmiendas al Anexo del Protocolo de 1997 que enmienda el Convenio Internacional para prevenir la contaminación por los buques, 1973, modificado por el Protocolo de 1978 (Convenio MARPOL), adoptadas mediante Resolución MEPC.271(69). Enmiendas a la regla 13 del Anexo VI del Convenio MARPOL (Prescripciones de registro para el cumplimiento operacional de las zonas de control de las emisiones de NOx del nivel III) ${ }^{15}$.

3. LA CULMINACIÓN DE LA REESTRUCTURACIÓN ORGANIZATIVA: EL NUEVO MINISTERIO DE AGRICULTURA Y PESCA, ALIMENTACIÓN Y MEDIO AMBIENTE

\footnotetext{
${ }^{11}$ BOE núm. 240, de 5 de octubre de 2017.

${ }^{12}$ BOE núm. 302, de 13 de diciembre de 2017.

${ }^{13}$ BOE núm. 1, de 1 de enero de 2018.

${ }^{14}$ BOE núm. 3, de 3 de enero de 2018.

${ }^{15}$ BOE núm. 3, de 3 de enero de 2018.
} 
En materia organizativa, el Real Decreto 895/2017, de 6 de octubre, ha desarrollado la estructura orgánica básica del Ministerio de Agricultura y Pesca, Alimentación y Medio Ambiente, establecido por el Real Decreto 415/2016, de 3 de noviembre, por el que se reestructuran los departamentos ministeriales. A este Departamento corresponde, en el ámbito de la Administración General del Estado, la propuesta y ejecución de la política del Gobierno en materia de lucha contra el cambio climático, protección del patrimonio natural, de la biodiversidad y del mar, agua, desarrollo rural, recursos agrícolas, ganaderos y pesqueros, y alimentación.

En particular, corresponde al Ministerio de Agricultura y Pesca, Alimentación y Medio Ambiente, en el ámbito de las competencias del Estado, la elaboración de la legislación estatal en materia de aguas y costas, medio ambiente y montes, meteorología y climatología; la propuesta y ejecución de las directrices generales del Gobierno sobre la política agraria, pesquera y alimentaria; la gestión directa del dominio público hidráulico, del dominio público marítimoterrestre; la representación del Estado en los organismos internacionales correspondientes a estas materias, sin perjuicio de las competencias del Ministerio de Asuntos Exteriores y de Cooperación; así como la coordinación de actuaciones, la cooperación y la concertación en el diseño y aplicación de todas las políticas que afecten al ámbito de competencias de las comunidades autónomas y de las restantes Administraciones públicas, propiciando su participación a través de los órganos e instrumentos de cooperación adecuados.

Estas competencias se entenderán en coordinación y sin perjuicio de aquéllas que corresponden a otros departamentos ministeriales. En particular, todas las competencias relacionadas con las instituciones de la Unión Europea o con organismos internacionales se ejercerán en coordinación con el Ministerio de Asuntos Exteriores y de Cooperación y, en su caso, con el Ministerio de Economía, Industria y Competitividad.

En cuanto a la estructura de este Ministerio, son órganos superiores y directivos del departamento, dependientes directamente del Ministro: la Secretaría de Estado de Medio Ambiente — de la cual dependen los siguientes órganos Directivos: la Dirección General del Agua, la Oficina Española de 
Cambio Climático, la Dirección General de Calidad y Evaluación Ambiental y Medio Natural y la Dirección General de Sostenibilidad de la Costa y del Mar-; la Subsecretaría de Agricultura y Pesca, Alimentación y Medio Ambiente - de la cual dependen los siguientes órganos directivos: la Dirección General de Producciones y Mercados Agrarios; la Dirección General de Sanidad de la Producción Agraria; la Dirección General de Desarrollo Rural y Política Forestal; y la Dirección General de la Industria Alimentaria-; la Secretaría General de Agricultura y Alimentación, con rango de Subsecretaría —de la cual dependen, con nivel orgánico de dirección general, la Secretaría General Técnica y la Dirección General de Servicios, y con nivel orgánico de subdirección general el Gabinete Técnico, la Inspección General de Servicios y la Subdirección General de Análisis, Prospectiva y Coordinación-; y la Secretaría General de Pesca, con rango de Subsecretaría - de la cual dependen los siguientes órganos directivos: la Dirección General de Recursos Pesqueros y la Dirección General de Ordenación Pesquera y Acuicultura-.

Asimismo, como órgano de apoyo y asistencia inmediata, depende directamente del Ministro de Agricultura y Pesca, Alimentación y Medio Ambiente un Gabinete.

Por último, cabe mencionar el organismo autónomo Parques Nacionales, que queda adscrito al Ministro, que lo presidirá; y la Agencia Estatal de Meteorología, adscrita al Ministerio de Agricultura y Pesca, Alimentación y Medio Ambiente a través de la Secretaría de Estado de Medio Ambiente.

\section{NOVEDADES NORMATIVAS EN ÁMBITOS SECTORIALES}

En el período objeto de análisis se han aprobado numerosas normas de rango reglamentario en materia ambiental, en ámbitos sectoriales diversos. Dada la imposibilidad de analizarlas todas ellas, nos limitamos a destacar aquellas que nos han parecido especialmente relevantes.

\subsection{En materia de medio marino}

A través del Real Decreto-ley 16/2017, de 17 de noviembre, por el que se establecen disposiciones de seguridad en la investigación y explotación de hidrocarburos en el medio marino, dictado al amparo de lo previsto en las 
reglas 13. ${ }^{a}, 18 .^{a}, 20 .^{a}$ y $25 .^{a}$ del artículo 149.1 de la $C E$, se incorpora parcialmente $-\mathrm{y}$ con retraso ${ }^{16}$ - al ordenamiento jurídico español la Directiva 2013/30/UE del Parlamento Europeo y del Consejo de 12 de junio de 2013, sobre la seguridad de las operaciones relativas al petróleo y al gas mar adentro, y que modifica la Directiva 2004/35/CE, que debería haber sido transpuesta al ordenamiento interno antes del 19 de julio de 2015.

Esta norma tiene por objeto establecer los requisitos mínimos que deben reunir las operaciones relacionadas con la investigación y explotación de hidrocarburos en el medio marino, para prevenir accidentes graves y limitar sus consecuencias. Asimismo, articula los principios de actuación para lograr que las citadas operaciones en el medio marino se lleven a cabo sobre la base de una gestión de riesgos sistemática, de manera que los riesgos residuales de accidentes graves puedan ser considerados aceptables.

En cuanto a su ámbito de aplicación, sus disposiciones serán de aplicación, exclusivamente en el medio marino, a los permisos de investigación de hidrocarburos y a las concesiones de explotación sean estas de yacimientos de hidrocarburos o de almacenamiento subterráneo para los mismos, así como a las operaciones asociadas a aquellos ${ }^{17}$. En el caso de que los permisos de investigación o las concesiones de explotación contengan, a la par, áreas situadas en medio terrestre y áreas situadas en el medio marino, este real decreto-ley les será de aplicación únicamente en caso de que se prevea la ejecución de operaciones asociadas a estos que se desarrollen en el medio marino.

Para dar cumplimiento a las finalidades establecidas, en el Capítulo II, incluye una serie de disposiciones relativas a permisos de investigación y concesiones

\footnotetext{
${ }^{16}$ Es precisamente este retraso el que justifica la adopción de un Decreto-ley para proceder su incorporación al ordenamiento jurídico español. Así se pone de manifiesto en el propio Preámbulo de la norma: "Ante la gravedad de las consecuencias de seguir acumulando retraso en la incorporación al ordenamiento jurídico español de la citada directiva, resulta necesario acudir a la aprobación de un real decreto-ley para proceder a su transposición, lo que permitirá cerrar los procedimientos de infracción abiertos y con ello evitar la imposición de sanciones económicas a España” (apartado V).

${ }^{17}$ Dichas operaciones en el medio marino "incluirán todas las actividades relativas a la investigación y producción de petróleo o gas asociadas a una instalación o una infraestructura conectada, incluidos el diseño, la planificación, la construcción, la explotación, el desmantelamiento y el abandono definitivo de la misma, estando excluido el transporte de petróleo y gas de costa a costa" (art. 2.1 del Real Decreto-ley 16/2017, de 17 de noviembre).
} 
de explotación de hidrocarburos en el medio marino. Así, establece requisitos de seguridad y medio ambiente para el otorgamiento o la transmisión de permisos de investigación y concesiones de explotación en el medio marino; y determina las obligaciones de los titulares de permisos de investigación y concesiones de explotación de hidrocarburos en el medio marino.

En el Capítulo III, recoge los principios a seguir en la gestión de riesgos relativos a las operaciones relacionadas con la investigación y explotación de hidrocarburos en el medio marino. Entre ellos, destacan el establecimiento de obligaciones para los operadores en medio marino y para los propietarios de instalaciones no destinadas a la producción, así como de obligaciones de remisión de información; la imposición —-también a los operadores en medio marino o los propietarios, según proceda - de la obligación de elaborar, para cada una de sus instalaciones, un informe sobre riesgos de accidentes graves, y de elaborar planes internos de emergencia que tendrán en cuenta el informe sobre los riesgos de accidentes graves y que formarán parte de éste; y la obligación de establecer programas de verificación independiente -con la finalidad de garantizar de manera independiente que los elementos críticos para la seguridad y el medio ambiente identificados en la evaluación de los riesgos para la instalación y descritos en el informe sobre los riesgos de accidentes graves, son adecuados, y que el calendario de examen y de prueba de los referidos elementos es adecuado, está actualizado y se ejecuta según las previsiones-y de responder al dictamen del verificador independiente y de tomar las medidas oportunas a partir del mismo.

En el Capítulo IV, determina las funciones de la Autoridad Competente para la Seguridad de las Operaciones Marinas en materia de Hidrocarburos (ACSOM).

En el Capítulo V, regula el plan externo de emergencia. Este plan, que será elaborado por el Ministerio de Fomento, en cooperación con los operadores en medio marino y los propietarios y, en su caso, los titulares, ACSOM y previo informe del resto de órganos con competencias en la materia, tendrá en cuenta la versión más reciente de los planes internos de emergencia de las instalaciones o infraestructuras conectadas existentes o planificadas en la zona y se realizará con la participación, en su caso, de las comunidades autónomas susceptibles de verse afectadas por dicho plan. El plan externo de emergencia 
abarcará el conjunto de todas las instalaciones de investigación y explotación de hidrocarburos en el medio marino, así como las infraestructuras conectadas y las áreas potencialmente afectadas. En él se especificará el cometido y las obligaciones financieras de los titulares y de los operadores en medio marino. Asimismo, el plan externo de emergencia específico para instalaciones de investigación y explotación de hidrocarburos se deberá integrar en los planes nacionales vigentes relativos al salvamento de la vida humana en el mar y a la lucha contra la contaminación del medio marino.

Por último, en el Capítulo VI, se recoge el régimen de infracciones y sanciones administrativas en esta materia, adecuándose el régimen sancionador a lo dispuesto en la Directiva 2013/30/UE e introduciéndose nuevos tipos específicos de infracciones derivados del incumplimiento de lo previsto en este Real Decreto-ley.

\subsection{En materia de patrimonio natural y biodiversidad}

En materia de patrimonio natural y biodiversidad, debe mencionarse el Real Decreto 7/2018, de 12 de enero, por el que se establecen los requisitos de documentación, tenencia y marcado en materia de comercio de especies amenazadas de fauna y flora silvestres, de acuerdo con lo establecido por la reglamentación de la Unión Europea en aplicación de la Convención sobre el comercio internacional de especies amenazadas de fauna y flora silvestre.

Este Real Decreto, dictado al amparo de lo dispuesto en el artículo 149.1.10. ${ }^{\text {a }}$ de la $C E$, que atribuye al Estado la competencia exclusiva en materia de régimen aduanero y arancelario y comercio exterior, tiene por objeto regular la forma de acreditar el origen legal de los especímenes de especies animales y vegetales incluidas en los anexos $A, B$ y $C$ del Reglamento (CE) n. ${ }^{\circ} 338 / 97$, de 9 de diciembre de 1996, relativo a la protección de especies de la fauna y flora silvestres mediante el control de su comercio, así como, asegurar la legalidad de todas las transacciones que impliquen un cambio de su titularidad. Se trata, en definitiva, de determinar la documentación mínima exigible que debe aportar el último propietario de los especímenes de las especies incluidas en los anexos A, B y C, como prueba de su origen legal, en cumplimiento de lo establecido en la reglamentación anteriormente citada, asegurando el 
necesario equilibrio entre el control del comercio de especies amenazadas de fauna y flora, y los medios exigibles a los ciudadanos, como prueba de que se cumplen las disposiciones en vigor.

Además, se pretende extender la obligatoriedad de marcado y los sistemas de marcado recogidos en el capítulo XVI del Reglamento (CE) n. ${ }^{\circ} 865 / 2006$, de 4 de mayo de 2006, por el que se establecen disposiciones de aplicación del Reglamento (CE) n. ${ }^{\circ}$ 338/97 del Consejo relativo a la protección de especies de la fauna y flora silvestres mediante el control de su comercio, a otros especímenes de especies incluidas en los anexos $A, B$ y $C$ del Reglamento (CE) n. ${ }^{\circ} 338 / 97$, de 9 de diciembre de 1996, con el fin de garantizar que los intercambios dentro de la Unión Europea de los citados especímenes tengan lugar en cumplimiento del marco legislativo vigente en ella. Asimismo, sobre los especímenes de especies incluidos en estos anexos, se establecen los requisitos documentales para que puedan ser considerados como nacidos y criados en cautividad, o reproducidos artificialmente.

Por otra parte, se incluye un anexo con el listado de especímenes vivos de especies exceptuadas del control establecido. Se trata de una serie de especímenes de especies, de carácter autóctono, tanto en España como en la Unión Europea, de elevado índice de reproducción y de escaso valor económico y comercial, y sobre las que no existe constancia de comercio ilegal, a las que no se considera necesario aplicar las disposiciones establecidas en este real decreto, siguiendo la línea establecida por la Unión Europea en la materia, que ha fijado determinadas excepciones en su reglamentación.

El Real Decreto consta de cinco artículos, que regulan el objeto, las definiciones, los medios de prueba que acrediten la tenencia legal, el marcado y los métodos del marcado de especímenes. Asimismo, la disposición adicional única hace referencia a la necesidad de que la autoridad administrativa principal notifique a la Comisión Europea y a la Secretaría de la Convención sobre el Comercio Internacional de Especies Amenazadas de Fauna y Flora Silvestre la aprobación y publicación de esta disposición, de acuerdo con las previsiones de los reglamentos europeos aplicables en la materia. 
Lo dispuesto en este real decreto se entenderá sin perjuicio de la legislación sectorial aplicable en materia de sanidad animal, vegetal o medioambiental establecidas para la importación, transporte nacional o dentro de la Unión Europea, o la tenencia de especies amenazadas de fauna y flora silvestres.

En otro orden de cosas, en materia de patrimonio natural y biodiversidad, mediante la Resolución de 13 de diciembre de 2017, de Parques Nacionales, se ha procedido a la publicación de la aprobación por la UNESCO de la ampliación de la Reserva de la Biosfera Marismas del Odiel, en Andalucía. Asimismo, mediante Resolución de 25 de enero de 2018, de la Dirección General de Calidad y Evaluación Ambiental y Medio Natural, se han incluido en el Inventario Español de Zonas Húmedas 83 nuevos humedales de la Comunidad Autónoma de Andalucía, tres de los cuales son resultado de la ampliación/fusión de humedales ya anteriormente incluidos, y se han reasignado códigos y modificado nombres de algunos sitios relacionados.

\subsection{En materia de fertilizantes}

En materia de fertilizantes, el Real Decreto 999/2017, de 24 de noviembre, ha procedido a la modificación del Real Decreto 506/2013, de 28 de junio, sobre productos fertilizantes, que establece la normativa básica en materia de productos fertilizantes, no considerados como "abonos CE" y las normas necesarias de coordinación con las comunidades autónomas. Con esta modificación, se pretende adaptar el marco normativo vigente en esta materia a la evolución del progreso técnico y científico, que ha facilitado el desarrollo de nuevos productos fertilizantes.

En particular, a través de esta modificación, se procede a actualizar el articulado del Real Decreto 506/2013, con el fin de contemplar los aspectos relacionados con microorganismos que pueden formar parte de un fertilizante para facilitar la disponibilidad de nutrientes para la planta, así como los anexos, para incluir nuevos tipos de productos (anexo I), actualizar las disposiciones sobre identificación y etiquetado (anexo II), modificar un margen de tolerancia (anexo III), establecer los métodos de análisis para estos nuevos productos (anexo VI) y corregir un error en las instrucciones para la inclusión de un nuevo tipo de fertilizante (anexo VII). Además, se añade un anexo VIII que establece 
los requisitos específicos de los productos fertilizantes elaborados con microorganismos.

Asimismo, también se procede a adaptar el procedimiento de inscripción en el Registro de productos fertilizantes a la Ley 39/2015, de 1 de octubre, de procedimiento administrativo común de las administraciones públicas y a sustituir las referencias a la Ley 30/1992, de 26 de noviembre, por las correspondientes a la nueva Ley.

\subsection{En materia de aguas}

En materia de aguas, dos son las normas más destacables. Por un lado, debe mencionarse la Ley $1 / 2018$, de 6 de marzo, por la que se adoptan medidas urgentes para paliar los efectos producidos por la sequía en determinadas cuencas hidrográficas y se modifica el texto refundido de la Ley de Aguas, aprobado por el Real Decreto Legislativo 1/2001, de 20 de julio ${ }^{18}$.

Esta norma se adopta con tres finalidades fundamentales. En primer lugar, tiene por objeto establecer medidas de apoyo y, en su caso, la concesión de ayudas a los titulares de las explotaciones agrarias situadas en los ámbitos territoriales afectados por la sequía ${ }^{19}$ en el año agrícola en que se adopta, que hayan sufrido pérdidas de producción bruta en los cultivos 0 en los aprovechamientos ganaderos de, al menos, un 20 por ciento de la producción

\footnotetext{
${ }^{18}$ Esta Ley se dicta al amparo del artículo 149.1.22 de la CE, que atribuye al Estado competencia exclusiva en materia de legislación, ordenación y concesión de recursos y aprovechamientos hidráulicos cuando las aguas discurran por más de una comunidad autónoma. De este título competencial se exceptúan los preceptos o parte de los mismos que se citan a continuación:

- El artículo 3 que se dicta al amparo del artículo 149.1.17 CE que atribuye al Estado la competencia sobre «régimen económico de la Seguridad Social, sin perjuicio de la ejecución de sus servicios por las comunidades autónomas».

- Los artículos 4, 7 y la disposición adicional primera que se dictan al amparo del artículo 149.1.14 CE en materia de Hacienda general y Deuda del Estado.

- Los artículos 5, 6, 8, 9 y la disposición adicional tercera que se dictan al amparo del artículo 149.1.1.13 $\mathrm{CE}$ que atribuye al Estado la competencia sobre Bases y coordinación de la planificación general de la actividad económica.

- Las disposiciones finales primera, segunda y tercera se regirán por el título competencial que se establece en la norma objeto de modificación (vid. la disposición final $4^{\text {a }}$ de la Ley 1/2018, de 6 de marzo).

${ }^{19}$ Los ámbitos territoriales afectados en orden a la aplicación de las medidas previstas se delimitarán, con carácter de urgencia, por orden del Ministerio de Agricultura y Pesca, Alimentación y Medio Ambiente (art. 1.2 de la Ley 1/2018, de 6 de marzo).
} 
normal en zonas desfavorecidas, y de un 30 por ciento en las demás zonas, de conformidad con los criterios establecidos por la Unión Europea.

En segundo lugar, pretende paliar el desequilibrio económico producido a la Mancomunidad de los Canales del Taibilla y a los abastecimientos de la provincia de Almería en la parte que se suministran mediante el acueducto Tajo Segura debido al uso de recursos no habituales (pozos de sequía, contratos de cesión temporal de derechos, incremento de recursos no convencionales como el agua desalinizada), necesarios para garantizar el abastecimiento de sus poblaciones, como consecuencia de la situación de sequía declarada que sufre la demarcación hidrográfica del Segura. Con este fin, la potencial afección a los usos de abastecimiento que se puedan derivar de la sequía declarada, en abastecimientos de Canales del Taibilla y en Almería, tratará de ser evitada haciendo efectivo el principio legal que prioriza el abastecimiento urbano sobre los usos productivos. Asimismo, para posibilitar la continuidad de la actividad productiva de las explotaciones agrarias que están sufriendo los efectos de la sequía, el Gobierno considera necesario adoptar un conjunto de medidas, con carácter urgente, destinadas a paliar los efectos de esta importante adversidad climática, en el marco de la necesaria cooperación con las comunidades autónomas afectadas.

En tercer lugar, esta norma incrementa el tipo de gravamen correspondiente al canon por utilización de las aguas continentales para la producción de energía eléctrica, previsto en el artículo 112 bis del texto refundido de la Ley de Aguas, aprobado por Real Decreto Legislativo 1/2001, de 20 de julio, al objeto de mejorar la dotación a los órganos competentes del Ministerio de Agricultura y Pesca, Alimentación y Medio Ambiente y a los organismos de cuenca de los necesarios recursos para la protección y mejora de dicho dominio público. Se pretende, de este modo, reforzar las actuaciones de protección, mejora y regeneración de las masas de agua superficial en las cuencas hidrográficas, sin perjuicio de la reducción progresiva de la contaminación procedente de sustancias prioritarias y de la eliminación de forma gradual respecto a los vertidos, las emisiones y las pérdidas de sustancias peligrosas, en las que debe intensificar esfuerzos la Administración Hidráulica del Estado. Para la ejecución de estas actuaciones de protección medioambiental que revisten 
carácter de urgencia, se hace imprescindible dotar a los órganos competentes del Ministerio de Agricultura y Pesca, Alimentación y Medio Ambiente de los recursos económicos y técnicos necesarios que permitan una conservación eficaz del dominio público hidráulico. Es por ello que se incrementa el tipo de gravamen del canon por utilización de las aguas continentales para la producción de energía eléctrica, con el fin de alcanzar el objetivo de compaginar adecuadamente dos bienes constitucionales: el medio ambiente y el desarrollo económico.

Por último, debe tenerse en cuenta que esta Ley habilita al Gobierno para, mediante real decreto, declarar la aplicación de las medidas en ella previstas a otras situaciones de sequía, que, cumpliendo los requisitos establecidos en esta norma, puedan acaecer en cualquier parte del territorio nacional a lo largo del año hidrológico 2017-2018.

Por otro lado, debe traerse a colación el Real Decreto 126/2018, de 9 de marzo, por el que se aprueba el Plan de gestión del riesgo de inundación del distrito de cuenca fluvial de Cataluña ${ }^{20}$, según lo dispuesto en el artículo 13.4 del Real Decreto 903/2010, de 9 de julio, de evaluación y gestión de riesgos de inundación.

\subsection{En materia de protección de la atmósfera}

En materia de protección de la atmósfera, resulta de referencia obligada el Real Decreto 1042/2017, de 22 de diciembre, sobre la limitación de las emisiones a la atmósfera de determinados agentes contaminantes procedentes de las instalaciones de combustión medianas y por el que se actualiza el anexo IV de la Ley 34/2007, de 15 de noviembre, de calidad del aire y protección de la atmósfera. Esta norma, que tiene en su totalidad el carácter de legislación básica sobre protección del medio ambiente, incorpora al ordenamiento jurídico español la Directiva (UE) 2015/2193 del Parlamento Europeo y del Consejo, de 25 de noviembre de 2015, sobre la limitación de las emisiones a la

\footnotetext{
${ }^{20}$ Este Real Decreto se dicta al amparo de la habilitación contenida en la cláusula 13. a del artículo 149.1 de la Constitución, que atribuye al Estado la competencia exclusiva en materia de bases y coordinación de la planificación general de la actividad económica (vid. la disposición final $1^{\mathrm{a}}$ del Real Decreto 6/2018, de 12 de enero).
} 
atmósfera de determinados agentes contaminantes procedentes de las instalaciones de combustión medianas.

Este Real Decreto tiene como objeto, por una parte, establecer disposiciones específicas para controlar las emisiones a la atmósfera de dióxido de azufre $\left(\mathrm{SO}_{2}\right)$, óxidos de nitrógeno $\left(\mathrm{NO}_{\mathrm{x}}\right)$, monóxido de carbono $(\mathrm{CO})$ y partículas procedentes de las instalaciones de combustión medianas y, así, reducir las emisiones atmosféricas y los riesgos potenciales de esas emisiones para la salud humana y el medio ambiente; y, por otra, actualizar la parte del catálogo de actividades potencialmente contaminadoras de la atmósfera relacionada con instalaciones de combustión con códigos de actividad 01, 02 y 0301 contenida en el anexo IV de la Ley 34/2007, de 15 de noviembre, de calidad del aire y protección de la atmósfera.

En cuanto a su ámbito de aplicación, esta norma resulta de aplicación a todas las instalaciones de combustión con una potencia térmica nominal igual o superior a $1 \mathrm{MW}$ e inferior a $50 \mathrm{MW}$ ("instalaciones de combustión medianas") cualquiera que sea el combustible utilizado, ya sean de titularidad pública o privada. Asimismo, también se aplica a la combinación de nuevas instalaciones de combustión medianas, cualquiera que sea el tipo de combustible que utilicen, cuya potencia térmica nominal total sea igual o superior a $50 \mathrm{MW}$ térmicos, a menos que dicha combinación sea una instalación de combustión regulada por el capítulo V del Real Decreto 815/2013, de 18 de octubre, por el que se aprueba el reglamento de emisiones industriales y de desarrollo de la Ley 16/2002, de 1 de julio, de prevención y control integrados de la contaminación ${ }^{21}$.

El Real Decreto 1042/2017 se estructura en 12 artículos, en los que, además, del objeto y ámbito de aplicación, se establecen una serie de definiciones y se regulan aspectos diversos, tales como las normas de adición; las autorizaciones, comunicaciones y registro; los valores límite de emisión de las instalaciones medianas de combustión; las obligaciones de los titulares de instalaciones de combustión medianas; la garantía del cumplimiento y acreditación de los valores límite de emisión; la inspección; la eficiencia

\footnotetext{
${ }^{21}$ Asimismo, este Real Decreto recoge un listado de instalaciones de combustión a las cuales no resulta de aplicación (vid. su art. 2.3).
} 
energética; los requisitos de información y presentación de informes; y el régimen sancionador. El texto se completa con tres disposiciones adicionales y cinco disposiciones finales.

En cuanto a la disposición final $1^{\mathrm{a}}$, procede a actualizar la parte del catálogo de actividades potencialmente contaminadoras de la atmósfera que afecta a las instalaciones de combustión medianas. Se modifican algunas de las actividades pertenecientes a los subgrupos de actividad de la generación de electricidad para red pública -0101-, generación de calor para distritos urbanos -0102-, refino de petróleo -0103-, transformación de combustibles sólidos 0104-, minería del carbón -0105-, combustión en los sectores comercial e institucional -0201-, residencial -0202- y agrario -0203-, y combustión en los sectores industriales -0301-. Se equiparán los rangos de potencia con los de la Directiva y algunas de las actividades modificadas pasan a pertenecer al grupo "C", todo ello con el objeto de que se les puedan aplicar los requisitos establecidos en este Real Decreto en cuanto a régimen de intervención administrativa, plazos y controles de seguimiento de las emisiones, entre otros. Las actividades no contempladas en esta disposición final permanecen tal y como se establece en el anexo IV de la Ley 34/2007, de 15 de noviembre, y en el Real Decreto 100/2011, de 28 de enero, por el que se actualiza el catálogo de actividades potencialmente contaminadoras de la atmósfera y se establecen las disposiciones básicas para su aplicación.

Por último, este Real Decreto incluye cuatro anexos con la información contenida en los anexos de la Directiva (UE) 2015/2193 del Parlamento Europeo y del Consejo, de 25 de noviembre de 2015.

\subsection{En materia de responsabilidad medioambiental}

En materia de responsabilidad medioambiental, debe traerse a colación la Orden APM/1040/2017, de 23 de octubre, por la que se establece la fecha a partir de la cual será exigible la constitución de la garantía financiera obligatoria para las actividades del anexo III de la Ley 26/2007, de 23 de octubre, de responsabilidad medioambiental, clasificadas como nivel de prioridad 1 y 2 , mediante Orden ARM/1783/2011, de 22 de junio, y por la que se modifica su anexo, cuya aprobación supone la culminación del proceso de reforma de la 
normativa de responsabilidad medioambiental, iniciado con la aprobación de la Ley 11/2014, por la que se modificó la Ley 26/2007, de 23 de octubre, y del Real Decreto 183/2015, de 13 de marzo, por el que se modificó el Reglamento de desarrollo parcial de la ley ${ }^{22}$.

Las actividades clasificadas con nivel de prioridad 1 -entre las cuales se encuentran las sujetas al ámbito de aplicación del Real Decreto de aprobación de medidas de control de los riesgos inherentes a los accidentes graves en los que intervengan sustancias peligrosas (SEVESO), así como determinadas actividades incluidas en el anexo I del Texto refundido de la Ley de prevención y control integrados de la contaminación, como por ejemplo, las instalaciones de combustión con una potencia térmica nominal igual o superior a $50 \mathrm{MW}$ y las instalaciones para la valorización o eliminación de residuos peligrosos con una capacidad de tratar más de 10 toneladas por día- deberán disponer de una garantía financiera en el plazo de un año a contar desde la entrada en vigor de la Orden, es decir, antes del 1 de noviembre de 2018. En cambio, las actividades clasificadas con nivel de prioridad 2 —entre las que se encuentran algunas de las incluidas en el anexo I del Texto refundido de la Ley de prevención y control integrados de la contaminación, concretamente determinadas refinerías de petróleo y gas, determinadas instalaciones de producción y transformación de metales, de la industria química o de gestión de residuos - deberán disponer de una garantía financiera en el plazo de dos años a contar desde su entra en vigor, es decir, antes del 1 de noviembre de 2019.

\section{OTRAS NORMAS DE INTERÉS}

Además de las normas reseñadas, en el período objeto de análisis pueden mencionarse otras normas de interés en ámbitos sectoriales diversos. Destacamos, entre ellas, en materia de residuos, la Orden APM/1007/2017, de 10 de octubre, sobre normas generales de valorización de materiales naturales excavados para su utilización en operaciones de relleno y obras distintas a

\footnotetext{
${ }^{22}$ Esta orden ministerial se dicta al amparo de lo dispuesto en el artículo 149.1.23. a de la Constitución, que atribuye al Estado la competencia sobre legislación básica de protección del medio ambiente y en el artículo 149.1.11. a de la Constitución, que atribuye al Estado la competencia sobre las bases de la ordenación de seguros (vid. su disposición final $2^{\mathrm{a}}$ ).
} 
aquéllas en las que se generaron; la Orden APM/189/2018, de 20 de febrero, por la que se determina cuándo los residuos de producción procedentes de la industria agroalimentaria destinados a alimentación animal, son subproductos con arreglo a la Ley 22/2011, de 28 de julio, de residuos y suelos contaminados; la Orden APM/205/2018, de 22 de febrero, por la que se establecen los criterios para determinar cuándo el aceite usado procesado procedente del tratamiento de aceites usados para su uso como combustible deja de ser residuo con arreglo a la Ley 22/2011, de 28 de julio, de residuos y suelos contaminados; y la Orden APM/206/2018, de 22 de febrero, por la que se establecen los criterios para determinar cuándo el fuel recuperado procedente del tratamiento de residuos MARPOL tipo c para su uso como combustible en buques deja de ser residuo con arreglo a la Ley 22/2011, de 28 de julio, de residuos y suelos contaminados. En materia de suelos, la Orden PARA/1080/2017, de 2 de noviembre, por la que se modifica el anexo I del Real Decreto 9/2005, de 14 de enero, por el que se establece la relación de actividades potencialmente contaminantes del suelo y los criterios y estándares para la declaración de suelos contaminados. En materia de vertidos, la Orden APM/130/2018, de 25 de enero, por la que se determinan las especificaciones técnicas para el envío de la información al Censo Nacional de Vertidos. En materia de eficiencia energética, la Orden ETU/257/2018, de 16 de marzo, por la que se establecen las obligaciones de aportación al Fondo Nacional de Eficiencia Energética en el año 2018. Y, en materia de costas, la Orden APM/241/2018, de 23 de febrero, por la que se aprueba el pliego de condiciones generales para el otorgamiento de concesiones demaniales con arreglo a lo establecido en la disposición transitoria $1^{\text {a }}$ de la Ley 22/1988, de 28 de julio, de costas.

En otro orden de cosas, también debe traerse a colación, en materia de contratación pública, el Real Decreto 6/2018, de 12 de enero, por el que se crea la Comisión Interministerial para la incorporación de criterios ecológicos en la contratación pública, adscrita como órgano colegiado al Ministerio de Agricultura y Pesca, Alimentación y Medio Ambiente y que tiene como finalidad garantizar la coordinación de la Administración General del Estado (AGE), sus Organismos Públicos y los servicios comunes y las Entidades Gestoras de la 
Seguridad Social, en la incorporación y el uso de criterios ecológicos en la contratación pública. 